Kansas State University Libraries

New Prairie Press

\title{
ARE SPATIAL MODELS NEEDED WITH ADEQUATELY BLOCKED FIELD TRIALS?
}

Reid D. Landes

Kent M. Eskridge

P. Stephen Baenziger

David B. Marx

See next page for additional authors

Follow this and additional works at: https://newprairiepress.org/agstatconference

Part of the Agriculture Commons, and the Applied Statistics Commons

\section{(c) (1) $\Theta$}

This work is licensed under a Creative Commons Attribution-Noncommercial-No Derivative Works 4.0 License.

\section{Recommended Citation}

Landes, Reid D.; Eskridge, Kent M.; Baenziger, P. Stephen; and Marx, David B. (2001). "ARE SPATIAL MODELS NEEDED WITH ADEQUATELY BLOCKED FIELD TRIALS?," Conference on Applied Statistics in Agriculture. https://doi.org/10.4148/2475-7772.1227

This is brought to you for free and open access by the Conferences at New Prairie Press. It has been accepted for inclusion in Conference on Applied Statistics in Agriculture by an authorized administrator of New Prairie Press. For more information, please contact cads@k-state.edu. 
Author Information

Reid D. Landes, Kent M. Eskridge, P. Stephen Baenziger, and David B. Marx 


\title{
ARE SPATIAL MODELS NEEDED WITH ADEQUATELY BLOCKED FIELD TRIALS?
}

\author{
Reid D. Landes ${ }^{1}$, Kent M. Eskridge ${ }^{2}$, P. Stephen Baenziger ${ }^{3}$, David B. Marx ${ }^{2}$ \\ ${ }^{1}$ Division of Biometry, University of Arkansas for Medical Sciences; Little Rock, AR. \\ ${ }^{2}$ Department of Biometry, University of Nebraska; Lincoln, NE. \\ ${ }^{3}$ Department of Agronomy, University of Nebraska; Lincoln, NE.
}

\begin{abstract}
The use of nearest neighbors and spatial models (SPAT) to analyze field trial data has become commonplace in recent years. These two types of analyses improve precision compared to ANOVA when trials are poorly blocked, but results are less clear in well-blocked trials. We examined data from wheat trials containing 60 cultivars, conducted at five locations, where each location was set up as an alpha lattice design. We compared the relative efficiency of detecting cultivar differences for spatial models and nearest neighbors analyses (NNA) to ANOVA, fit of the models, and correlations of ranked cultivars. Though the SPAT and NNA generally outperformed the ANOVA, the selection of desirable cultivars remained relatively unchanged when using a well-blocked design analyzed with an ANOVA.
\end{abstract}

\section{INTRODUCTION}

The primary interest in field crop breeding is to develop a robust, high yielding cultivar. To do so, a series of field trials must be conducted in order to identify the cultivars that have the most potential and accurately "weed out" the cultivars that, by chance, are fortunate enough to have outlying observations that pull up their means. Field trials designed with these goals in mind are typically conducted at several locations, with each location being set up as a complete block design, and analyzed with an ANOVA. The resulting means from each location are ranked and, in consideration of the ranked means from other locations, selections of advancing cultivars are made.

Often there are a large number of cultivars to be tested. And in the complete block setting, non-uniformity of plots within a block is core to the statistical problems. This leads to a large error variance, and ultimately results in Type II errors - that is, the breeder may not be able to distinguish true high yielding cultivars from others, especially when the differences between cultivars are relatively small. Though missing the proverbial "bin buster" does not incur actual losses, it does lose the potential of high earnings.

In attempts to address these problems, either nearest neighbors analysis (NNA) or spatial models (SPAT) have been used in conjunction with RCBD experiments (Stroup et. al., 1994; Zimmerman et. al., 1991). These methods often substantially improve precision relative to ANOVA. However, improved experimental design is not often considered. If smaller, incomplete blocks are used and analyzed by ANOVA, the cultivar selection decisions to be made may be sufficiently similar to those reached using the analyses incorporating information from neighboring plots as to justify the foregoing of the effort required for more sophisticated 
analyses. In addition, a combination of better designs and spatially adjusted analyses might be a considerable improvement over these other methods.

Though much has been done to compare RCBD-ANOVA with incomplete block designs (IBD-ANOVA) (Cochran, et. al. 1957), and spatial models (i.e. SPAT and NNA), very little has been done to compare IBD-ANOVA with spatial models. The objectives of this paper are to compare RCBD-ANOVA, IBD-ANOVA, NNA, and SPAT regarding the detection of cultivar differences using data from the USDA-University of Nebraska wheat breeding program.

\section{MATERIALS \& METHODS}

For this study, the 2000 Nebraska Intrastate Nursery (NIN) trial was used. The NIN was an advanced yield trial that consisted of 12 check cultivars and 48 experimental cultivars for possible release. It was conducted at six locations in Nebraska, however one location was not used for analysis due to errors in the layout of the experimental design. The remaining five locations were Alliance, Lincoln, McCook, Mead, and Sidney. Recommended seeding rates and cultural practices were used throughout. There were two replicates at McCook and Mead, and four replicates at the remaining three locations. Each location was planted as a resolvable alphalattice design with contiguous replicates having 10 incomplete blocks of 6 cultivars each (Patterson, H. O, et. al., 1976). Thus, the field could be analyzed with an ANOVA assuming an incomplete block (IBD), complete block (RCBD), or completely randomized design (CRD).

Yield expressed in bushels/acre were analyzed for each location with ANOVA, NNA, and SPAT. For each location, the CRD, RCBD, and IBD linear models were

$$
y_{i j}=\mu+\tau_{i}+b_{j}+e_{i j},
$$

where $y_{i j}$ was the response from the $j^{\text {th }}$ replicate of the $i^{\text {th }}$ cultivar, $\mu$ was the overall mean, and $\tau_{i}$ was the mean of the $i^{t h}$ cultivar. For the RCBD and IBD, the $b_{j}$ was the random error associated with block and was assumed to be independent having a mean of zero and variance of $\sigma_{b}^{2}$. The $b_{j}$ term was set to zero for the CRD. The $e_{i j}$ was the residual error assumed to be independently and identically distributed with a mean of zero and variance of $\sigma^{2}$. Locations were analyzed separately to allow modeling of different spatial structures at each site.

The NNA method used the residuals from adjacent plots as a covariate added to the ANOVA model to correct for within-block variability. The covariates were computed using the method as described by Papadakis (1937). For example, the East-West covariate was constructed as $1 / 2\left(r_{i-1, j}+r_{i+1, j}\right)$ where $r_{i, j}=y_{i, j}-\left(\bar{y}_{i, j}\right)$ with $\bar{y}_{i, j}$ being the mean of the cultivar found in the $i j^{\text {th }}$ plot. The $i$ corresponded to the East-West index, and the $j$ to the North-South index. The error terms remained the same.

The analyses for the SPAT used the same fixed effects of the ANOVA models, as well as the same variance structure for the random block effect. However, the residual errors were assumed to have a mean of zero and a spatial variance-covariance structure, $\Sigma$. The off-diagonal elements of $\Sigma$ were a function of distance from the $i j^{\text {th }}$ plot for the isotropic structures, and the inclusion of direction from the $i j^{\text {th }}$ plot for the anisotropic structures.

At each location, the data were first analyzed with ANOVA assuming three different experimental designs - CRD, RCBD, and IBD. When analyzing the data with the NNA, under each experimental design, the following neighbor patterns were used as covariates: East-West 
(EW), North-South (NS), North-South-East-West (NSEW), North-South-East-West-Corners (NSEWC), and finally a model using the two covariates NS and EW as covariates. For the SPAT, each experimental design was analyzed with the following spatial covariance patterns available in SAS/STAT® (1997): spherical (SPH), exponential (EXP), gaussian (GAU), anisotropic power (POWA), anisotropic exponential (EXPA), anisotropic power with a nugget effect $(\mathrm{POWA}+\mathrm{N})$, and anisotropic exponential with a nugget effect $(\mathrm{EXPA}+\mathrm{N})$. Thus a total of $3+(3 \times 5)+(3 \times 7)=39$ analyses were performed for each location.

For all analyses, the denominator degrees of freedom of the test statistics were adjusted with the method described by Kenward and Roger (1997). This method adjusts the residual maximum likelihood estimator of the covariance matrix to reduce the bias resulting from small sample sizes $(<\infty)$. The covariance parameters were estimated using the residual maximum likelihood (REML) method.

To identify the best NN model for each location, we chose the NN covariate pattern that resulted in an Akaike Information Criterion (AIC) close to zero relative to the other patterns and a small MSE. The AIC is essentially the (residual) maximum likelihood estimate penalized for the number of covariance parameters, and can be used to compare models (Littel, et. al., 1996). Of all SPAT that were examined at each location two spatial structures were chosen. The "best" SPAT was the model that had an AIC close to zero relative to the others, and that closely agreed with the covariance estimates from the omnidirectional variogram (Isaaks, et. al. 1989). A "simple" SPAT was chosen for each location using the same criteria, but limited to the models with no blocking (i.e. CRD), and from spatial covariance patterns that are often used in practice, namely SPH, EXP, POWA, and EXPA.

Upon selecting a NNA and two SPAT models for each location, we compared their results with those from the RCBD and IBD-ANOVA in three different ways. The first method was a comparison of the precision of cultivar differences that was made with an estimate of relative efficiency. The estimated relative efficiency (ERE) is the ratio between the two models of the means of the standard errors of all pairwise cultivar differences. Large ratios $(>1.0)$ indicated that the method in the denominator had more power for detecting a specified difference. Secondly, we compared the AIC values of the different models with a model being preferred if its AIC was closer to zero. And finally, in order to assess the agreement between any two of the methods on the decisions made for the selection of cultivars, we correlated the ranks of the cultivars with the Spearman rank correlation coefficient.

\section{RESULTS AND DISCUSSION}

To choose the "best" NN covariate for each location, we examined the AIC and MSE. The selection process is demonstrated by way of example. Table 1 provides the NNA results of all design-covariate combinations for McCook. The greatest AIC occurred for the RCBDNSEWC model with a value of -218.3 , while the lowest MSE of 34.3 occurred for the IBD-NS model which had an AIC of -222.1. In comparison, the MSE from the RCBD-NSEWC model was 36.9. The design-covariate pattern chosen was the RCBD-NSEWC model since it had the smallest AIC and a reasonably small MSE. The selected NN models for each of the locations are presented in Table 3. 
Similarly, when selecting the "best" and "simple" SPAT, the models having an AIC relatively close to zero were likely candidates for selection. In addition, the covariance estimates were also taken into account with a view to the omnidirectional variogram estimates. It was the case more than once that a certain SPAT model would have an AIC relatively close to zero, but that the variance-covariance estimates were exceedingly far from the variogram's estimates. In these situations, the models were not good fits to the data due to the discordant covariance estimates. For the "best" SPAT, all covariance structures and designs were considered. As for the "simple" SPAT, only those covariance structures previously specified were considered in a CRD context. There were computational problems such as non-positive definite Hessians, too many likelihood evaluations, and non-convergence. Examples of all the problems we encountered in the SPAT analyses are presented in Table 2 for McCook. Covariance structures with computational problems were not considered for selection. For McCook the CRDPOWA+N was chosen as the "best" not only for having the AIC closest to zero (Table 2), but also for having an estimate of the sill of the variogram equal to $(117.59+16.06=) 133.65$ that was the closest to the variogram sill estimate of $\sim 190$ (Figure 1). The sill is the variance between plots considered to be independent; the range is the distance at which the plots are considered to be independent (Isaaks, et. al., 1989). For McCook, the range is estimated at 100 feet. In choosing the "simple" spatial covariance structure, the two "simple" structures having the greater AIC values in a CRD context were the SPH and EXP (Table 2). Even though the AIC for SPH is farther from zero than that for the EXP, the SPH sill and range estimates of 186.50 and 66.15 respectively, were the closest to those obtained from the variogram. Hence, the CRD-SPH was chosen as the "simple" SPAT. Selected SPAT models for each location are provided in Table 3.

When the analyses were done with ANOVA (results in Table 4), blocking was a significant improvement over no blocking at all locations except Mead. At Mead the lowest pvalue from the Residual Log Likelihood Chi-square test for significance of blocking was 0.1573. The Mead location was a very homogeneous field as demonstrated by virtually no change in the MSE when using blocks, and by an omnidirectional variogram that resulted in an approximate horizontal line (figure not shown). It was further demonstrated by the fact that the NNA and SPAT results showed no improvement over the CRD-ANOVA (results not shown). For three of the four remaining locations, the MSE from the RCBD-ANOVA ranged from $148-281 \%$ of that from the IBD-ANOVA; for Lincoln, the increase was only $105 \%$. However, the conclusions reached from the overall test for the effect of cultivars at each location remained unchanged between the three designs, save for Sidney, where the CRD-ANOVA had a non-significant $F$, while the $F$ was highly significant for the RCBD and IBD.

To compare the RCBD-ANOVA to the more sophisticated analyses within each location, we first looked at the estimated relative efficiency to the RCBD-ANOVA (ERE $E_{R C B}$ ) of detecting a cultivar difference. For IBD-ANOVA at McCook and Sidney, the ERE $E_{R C B}$ started at 1.76 and 2.31, respectively, and increased as the complexity of the model increased (Figure 2). Similarly for Alliance, the IBD-ANOVA, NNA, and "best" SPAT were clearly more precise than the $\mathrm{RCBD}$, with all having an $\mathrm{ERE}_{\mathrm{RCB}}$ of greater than 1.25; the "simple" SPAT was more efficient but not considerably so with an $\mathrm{ERE}_{\mathrm{RCB}}$ of 1.06. Only at the Lincoln site did the $\mathrm{ERE}_{\mathrm{RCB}}$ dip below one - the point at which the "new" model is the same as the "original" model in regard to precision. The IBD-ANOVA and "best" SPAT had an ERE $_{\mathrm{RCB}}$ of 0.95 and 0.58, respectively. Yet the NNA and "simple" SPAT both had an ERERCB of 1.37. 
We compared the AIC of the RCBD-ANOVA to the other models' AIC via the difference of the $\mathrm{AIC}$ values $\left(\mathrm{DA}_{\mathrm{RCB}}=\mathrm{AIC}_{\text {other }}-\mathrm{AIC} \mathrm{C}_{\mathrm{RCB}}\right)$. All of the methods across all of the locations followed the same pattern in the $\mathrm{DA}_{\mathrm{RCB}}$ (Figure 3). From lowest $\mathrm{DA}_{\mathrm{RCB}}$ to the highest, the methods were IBD-ANOVA, "simple" SPAT, "best" SPAT, and then NNA. Only for the IBDANOVA at Lincoln was the $\mathrm{DA}_{\mathrm{RCB}}$ negative - indicating that the RCBD-ANOVA was a better fit.

From a plant breeding perspective, comparing the methods to determine the amount of agreement in their selection decisions is a critical issue. To do this, we calculated the Spearman rank correlation coefficient of the ranked cultivars between the various methods. For if the selection decisions from a particular method are highly correlated with the selection decisions from all the other methods, then the decisions made from that particular method are robust.

Overall most correlations were greater than 0.85 indicating all models gave very similar cultivar rankings (Table 5). The correlation matrices by location show that the RCBD-ANOVA is most closely correlated with the IBD-ANOVA results for Alliance, Lincoln, and McCook. For Sidney, the RCBD-ANOVA results most closely correlate with those from the NNA. Though not all methods at all locations outperformed the RCBD-ANOVA, it is still evident that in general the use of either a more complicated design or analysis provided substantial improvement.

Comparing the precision of cultivar differences from the IBD-ANOVA with that from the NNA, the ERE $E_{\text {IBD }}$ was consistently greater than one, though at Alliance and Sidney, the NNA was not greater than 14\% more efficient (Figure 4). For the "best" and "simple" SPAT, the efficiency of the SPAT models depended on the location. At Alliance, the ERE $E_{\text {IBD }}$ for the "simple" SPAT was 0.84, while at the remaining locations, the "simple" SPAT was clearly preferable to the IBD-ANOVA with the lowest ERE $E_{\mathrm{IBD}}$ of these being 1.41. The ERE $\mathrm{IBD}_{\mathrm{IBD}}$ for the "best" SPAT outperformed the IBD-ANOVA for McCook and Sidney; however, the gain in efficiency using the "best" SPAT at Alliance was only slight, with the ERE $E_{\mathrm{IBD}}$ being 1.11. And at Lincoln, the IBD-ANOVA was estimated to be more efficient than the "best" SPAT (Figure 4).

In view of the AIC values (Figure 5), models taking into account information from surrounding plots consistently fit the data better than the did the IBD-ANOVA. The AIC values followed the same pattern at the four locations exhibiting some evidence of spatial structure. The NNA had AIC values closest to zero, the "best" SPAT had the second closest, and finally the "simple" SPAT had the third closest. For the 2000 NIN Trials, the methods taking into account spatial information did a better job of describing the data without fail at all of the locations (Mead not considered).

Regarding rank correlations of the cultivar means between the methods, the RCBDANOVA rankings were most often correlated the closest with the IBD-ANOVA results (Table 5). However, the converse was not true. IBD-ANOVA most closely correlated with the results from "best" SPAT at three of the locations, and at Lincoln, most closely correlated with the NNA results. This indicates that if we had used only the IBD-ANOVA to rank varieties, then we would have come to conclusions similar to the SPAT method, which takes into account the most information from the data. 


\section{SUMMARY}

Using data from the USDA-University of Nebraska wheat breeding program, the RCBDANOVA was generally inferior to using the IBD-ANOVA and also to the more complex analysis methods - NNA and SPAT - when comparing the estimated relative efficiency and AIC's of the methods. The lower rank correlations of the RCBD-ANOVA with the more sophisticated methods of analysis also give plant breeders an indication that the decisions made with the RCBD-ANOVA may well miss the "bin buster" they so hope to discover.

By using an incomplete block design, such as an alpha-lattice design, we were able to substantially increase the precision of the estimates of cultivar differences over the RCBDANOVA, but, in general, still more precision appeared to be gained from the NNA and SPAT analyses. The NNA was consistently more efficient than the IBD-ANOVA, though at two of the four locations for which the NNA was applied, the gain in efficiency did not exceed $15 \%$. As for the SPAT, gains in efficiency were dependent on the type of spatial covariance structure modeled. At two of the locations, one of the two SPAT models used were shown to be inefficient to the IBD-ANOVA. These results conflict with the use of the AIC as a measure of model fit to the data, which showed all of the spatially oriented models to be a better fit than the IBD-ANOVA. Nevertheless, the results from these comparative analyses for the wheat trial under consideration may give comfort to the plant breeder in that the cultivar rankings from the IBD-ANOVA were highly correlated with those made from the more efficient analysis methods - NNA and SPAT. 


\section{REFERENCES}

Cochran, W. G., et. al., (1957) Experimental Designs. John Wiley \& Sons, Inc. 611 pp.

Isaaks, E. H., et. al., (1989) An Introduction to Applied Geostatistics. Oxford University Press.

$561 \mathrm{pp}$.

Kenward, M. G., et. al., (1997) Small Sample Inference for Fixed Effects from Restricted Maximum Likelihood. Biometrics, 53:983-997.

Littel, R. C., et. al. SAS® System for Mixed Models. Cary, NC: SAS Institute Inc., 1996. $633 \mathrm{pp}$.

Papadakis, J. S., (1937) Methode statistique pour des experiences sur champ. Bull. Inst. Amelior. Plant. Thessalonique, 23.

Patterson, H. O., et. al., (1976) A New Class of Resolvable Incomplete Block Designs. Biometrika, 63:83-92.

SAS Institute Inc., (1997) SAS/STAT® Software: Changes and Enhancements through Release 6.12, Cary, NC: SAS Institute Inc. 1167 pp.

Stroup, W.W., et. al., (1994) Removing Spatial Variation from Wheat Yield Trials: A Comparison of Methods. Crop Science, 34:62-66.

Zimmerman, D. L., et. al., (1991) A Random Field Approach of the Analysis of Field- $\quad$ Plot Experiments and Other Spatial Experiments. Biometrics, 47:223-239. 
Table 1

Nearest Neighbor Information for McCook

\begin{tabular}{|l|l|l|l|l|}
\hline Design & Covariate(s) & AIC & MSE & Variety p-value \\
\hline CRD & EW & -234.9 & 69.4 & 0.1366 \\
\hline & NS & -223.2 & 46.6 & $*$ \\
\hline & NSEW & -221.7 & 44.4 & $*$ \\
\hline & NSEWC & -220.4 & 42.7 & $*$ \\
\hline & NS \& EW & -221.7 & 43.6 & $*$ \\
\hline RCBD & EW & -234.9 & 69.4 & 0.1366 \\
\hline & NS & -223.2 & 46.6 & $*$ \\
\hline & NSEW & -221.7 & 41.9 & $*$ \\
\hline & NSEWC & -218.3 & 36.9 & $*$ \\
\hline IBD & NS \& EW & -222.2 & 41.9 & $*$ \\
\hline & EW & -235.3 & 56.4 & 0.3159 \\
\hline & NS & -222.1 & 34.3 & 0.0535 \\
\hline & NSEW & -222.3 & 40.3 & 0.0727 \\
\hline & NSEWC & -220.6 & 36.7 & 0.0681 \\
\hline & NS \& EW & -221.7 & 35.7 & 0.0603 \\
\hline
\end{tabular}

An * indicates a p-value of less than 0.05 .

Table 2

Spatial model information for McCook

\begin{tabular}{|l|l|l|l|l|l|l|}
\hline Model & $\begin{array}{l}\text { Est. } \\
\text { Range }\end{array}$ & $\begin{array}{l}\text { Est. } \\
\text { Sill }\end{array}$ & $\begin{array}{l}\text { Est. } \\
\text { Nugget }\end{array}$ & AIC & $\begin{array}{l}\text { Variety } \\
\text { p-value }\end{array}$ & Notes \\
\hline CRD SPH & 66.15 & 186.50 & $* *$ & -224.0 & .0002 & \\
\hline CRD EXP & 64.16 & 276.38 & $* *$ & -223.4 & .0001 & \\
\hline *CRD GAU & 8.73 & 133.60 & $* *$ & -238.9 & $--x--$ & No denominator d.f. \\
\hline CRD POWA & $* *$ & 99.85 & $* *$ & -225.2 & .0057 & \\
\hline CRD EXPA & $* *$ & 99.73 & $* *$ & -226.8 & .2855 & \\
\hline CRD POWA+N & $* *$ & 117.59 & 16.06 & -221.2 & .0869 & \\
\hline CRD EXPA+N & $* *$ & 144.83 & 17.06 & -221.8 & .1243 & \\
\hline RCBD SPH & 66.15 & 186.50 & $* *$ & -224.0 & .0002 & \\
\hline RCBD EXP & 64.19 & 276.49 & $* *$ & -223.4 & .0016 & \\
\hline *RCBD GAU & $--x--$ & $--x--$ & $* *$ & $--x--$ & $--x--$ & Too many likelihood evaluations \\
\hline *RCBD POWA & $* *$ & 99.84 & $* *$ & -225.2 & -- x-- & No denominator d.f. \\
\hline *RCBD EXPA & $* *$ & 99.72 & $* *$ & -226.8 & $--x--$ & No denominator d.f. \\
\hline RCBD POWA+N & $* *$ & 117.59 & 16.06 & -221.2 & .2821 & \\
\hline *RCBD EXPA+N & $* *$ & 144.83 & 17.06 & -221.8 & 1.000 & Numerator d.f.=3 \\
\hline IBD SPH & 66.02 & 162.97 & $* *$ & -224.6 & .0082 & \\
\hline IBD EXP & 86.13 & 322.44 & $* *$ & -224.1 & .0047 & \\
\hline *IBD GAU & $--\mathrm{x}--$ & $--\mathrm{x}--$ & $* *$ & $--\mathrm{x}--$ & $--\mathrm{x}--$ & Did not converge \\
\hline IBD POWA & $* *$ & 99.84 & $* *$ & -225.2 & .0057 & \\
\hline *IBD EXPA & $* *$ & 45.08 & $* *$ & -237.7 & .3436 & Hessian not positive definite \\
\hline *IBD POWA+N & $* *$ & 16.79 & 25.63 & -241.0 & .2775 & Hessian not positive definite \\
\hline IBD EXPA+N & $* *$ & 144.85 & 17.06 & -221.8 & .1241 & \\
\hline
\end{tabular}

An * indicates the model was not considered for selection due to computational errors. An ** "Not Applicable". An --X-- indicates "Not available" due to computational errors. 
Table 3

Chosen Models and their Results for all Locations

\begin{tabular}{|c|c|c|c|c|}
\hline Location-Method & Model & AIC & $\begin{array}{c}\text { Mean s.e. of } \\
\text { difference }\end{array}$ & $\begin{array}{c}\text { Variety effect } \\
\text { p-value }\end{array}$ \\
\hline Alliance-ANOVA & CRD & -697.7 & 6.51 & .0070 \\
\hline Alliance-ANOVA & RCBD & -675.8 & 5.59 & .0001 \\
\hline Alliance-ANOVA & IBD & -668.1 & 4.99 & .0001 \\
\hline Alliance-NNA & CRD-NS \& EW & -643.6 & 4.78 & .0002 \\
\hline Alliance- SPAT best & CRD POWA+N & -656.4 & 4.73 & .0001 \\
\hline Alliance- SPAT simple & CRD EXPA & -659.4 & 5.43 & .0001 \\
\hline Lincoln-ANOVA & CRD & -737.1 & 8.11 & .5074 \\
\hline Lincoln-ANOVA & RCBD & -730.4 & 7.63 & .2892 \\
\hline Lincoln-ANOVA & IBD & -734.4 & 7.83 & .3157 \\
\hline Lincoln-NNA & CRD-NSEW & -698.1 & 6.51 & .0560 \\
\hline Lincoln-SPAT best & RCBD-EXPA & -706.7 & 10.06 & .6212 \\
\hline Lincoln-SPAT simple & CRD-EXP & -716.2 & 6.55 & .0246 \\
\hline McCook-ANOVA & CRD & -258.3 & 12.47 & .8331 \\
\hline McCook-ANOVA & RCBD & -247.1 & 9.87 & .2047 \\
\hline McCook-ANOVA & IBD & -239.0 & 7.45 & .2776 \\
\hline McCook-NNA & RCBD-NSEWC & -218.3 & 6.14 & .0111 \\
\hline McCook-SPAT best & CRD-POWA+N & -221.2 & 5.81 & .0869 \\
\hline McCook-SPAT simple & CRD-SPH & -224.0 & 5.15 & .0002 \\
\hline Mead-ANOVA & CRD & -214.5 & 6.00 & .0001 \\
\hline Sidney-ANOVA & CRD & -757.9 & 9.10 & .7091 \\
\hline Sidney-ANOVA & RCBD & -710.7 & 6.74 & .0095 \\
\hline Sidney-ANOVA & IBD & -667.8 & 4.43 & .0001 \\
\hline Sidney-NNA & CRD-NS \& EW & -618.7 & 4.15 & .0001 \\
\hline Sidney- SPAT best & CRD-POWA+N & -626.3 & 3.89 & .0001 \\
\hline Sidney- SPAT simple & CRD-POWA & -645.5 & 3.73 & .0001 \\
\hline
\end{tabular}

Table 4

ANOVA Results and AIC for all Locations

\begin{tabular}{|c|c|c|c|}
\hline Location \& Model & MSE & Variety p-value & AIC \\
\hline Alliance - CRD & 84.88 & 0.0070 & -697.7 \\
\hline Alliance - RCBD & 62.49 & $<.0001$ & -675.8 \\
\hline Alliance - IBD & 42.13 & $<.0001$ & -668.1 \\
\hline Lincoln - CRD & 131.47 & 0.5074 & -737.1 \\
\hline Lincoln - RCBD & 116.44 & 0.2892 & -730.4 \\
\hline Lincoln - IBD & 110.86 & 0.3157 & -734.4 \\
\hline McCook - CRD & 155.48 & 0.8331 & -258.3 \\
\hline McCook - RCBD & 97.35 & 0.2047 & -247.1 \\
\hline McCook - IBD & 42.42 & 0.2776 & -239.0 \\
\hline Mead - CRD & 36.03 & .0001 & -214.5 \\
\hline Mead - RCBD & 36.03 & .0001 & -214.5 \\
\hline Mead - IBD & 34.23 & .0001 & -215.4 \\
\hline Sidney - CRD & 165.70 & 0.7091 & -757.9 \\
\hline Sidney - RCBD & 90.84 & 0.0095 & -710.7 \\
\hline Sidney-IBD & 32.37 & $<.0001$ & -667.8 \\
\hline
\end{tabular}


Table 5

Spearman Rank Correlations between Models

Alliance
\begin{tabular}{|l|l|l|l|l|l|}
\hline & RCBD & IBD & NNA & "best" SPAT & "simple" SPAT \\
\hline RCBD & 1 & .93726 & .93259 & .92053 & .92448 \\
\hline IBD & & 1 & .95349 & .97610 & .97210 \\
\hline NNA & & & 1 & .97488 & .98149 \\
\hline "best" SPAT & & & & 1 & .99517 \\
\hline
\end{tabular}

\section{Lincoln}

\begin{tabular}{|l|l|l|l|l|l|}
\hline & RCBD & IBD & NNA & "best" SPAT & "simple" SPAT \\
\hline RCBD & 1 & .98038 & .88008 & .82134 & .85307 \\
\hline IBD & & 1 & .90331 & .83562 & .86880 \\
\hline NNA & & & 1 & .93787 & .94293 \\
\hline "best" SPAT & & & & 1 & .90103 \\
\hline
\end{tabular}

\section{McCook}

\begin{tabular}{|l|l|l|l|l|l|}
\hline & RCBD & IBD & NNA & "best” SPAT & "simple” SPAT \\
\hline RCBD & 1 & .81128 & .69797 & .73404 & .67641 \\
\hline IBD & & 1 & .86952 & .90342 & .76655 \\
\hline NNA & & & 1 & .94460 & .87369 \\
\hline 'best" SPAT & & & & 1 & .90586 \\
\hline
\end{tabular}

\section{Sidney}

\begin{tabular}{|l|l|l|l|l|l|}
\hline & RCBD & IBD & NNA & "best" SPAT & "simple" SPAT \\
\hline RCBD & 1 & .73859 & .72665 & .74565 & .71887 \\
\hline IBD & & 1 & .87441 & .93437 & .87530 \\
\hline NNA & & & 1 & .95643 & .96649 \\
\hline "best" SPAT & & & & 1 & .93676 \\
\hline
\end{tabular}

For all correlations, $\mathrm{n}=60$, and all are significant at the .0001 level. 
Figure 1

Omnidirectional Variogram

for McCook

\section{MCCOOK}

\section{Variogram}

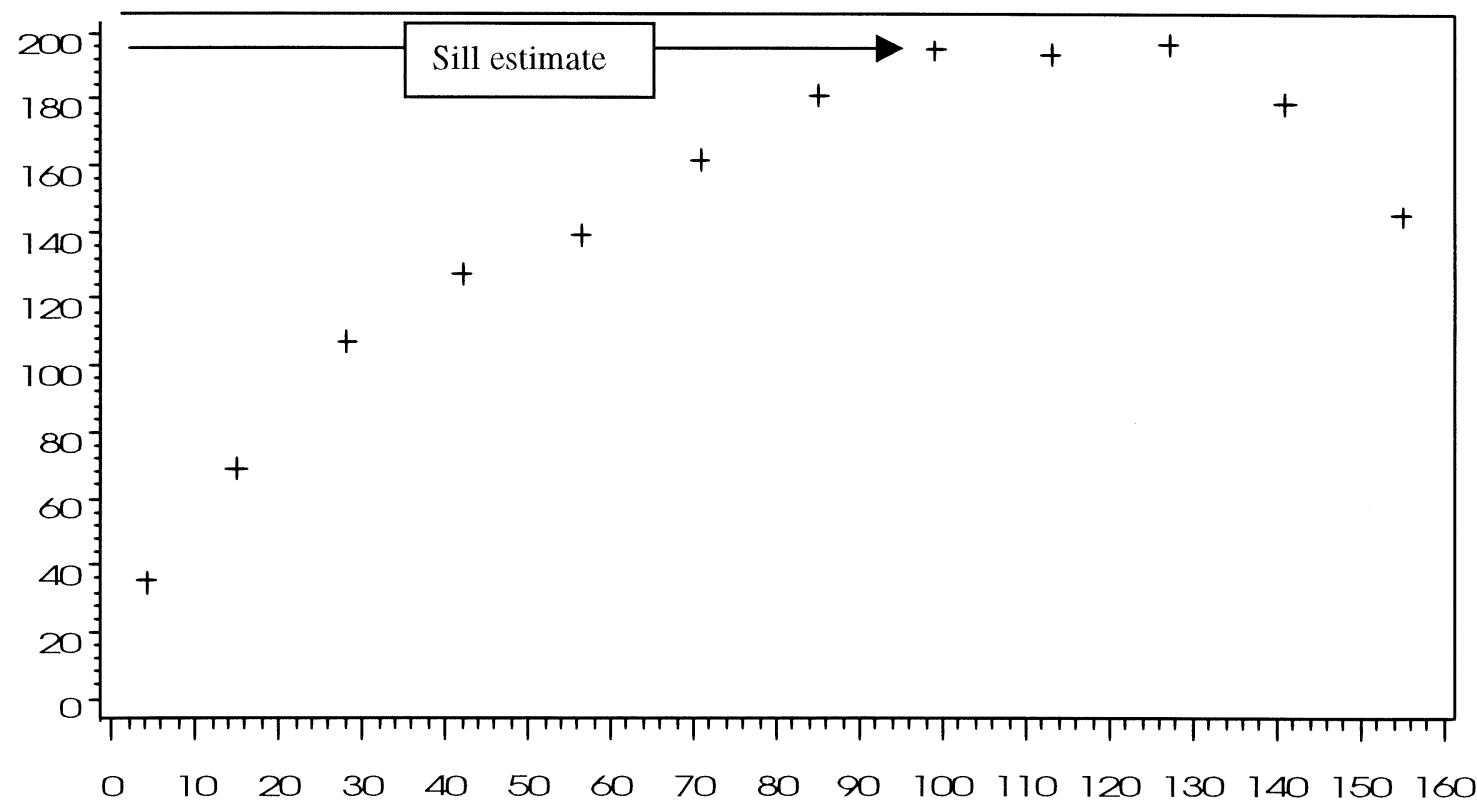

Avg. Lag Distance for Class

Figure 1: Distance is expressed in feet. A lag distance of $14 \mathrm{ft}$. provided the smoothest variogram for this particular location. The variogram value is half the mean squared difference between the paired data values. 
Figure 2

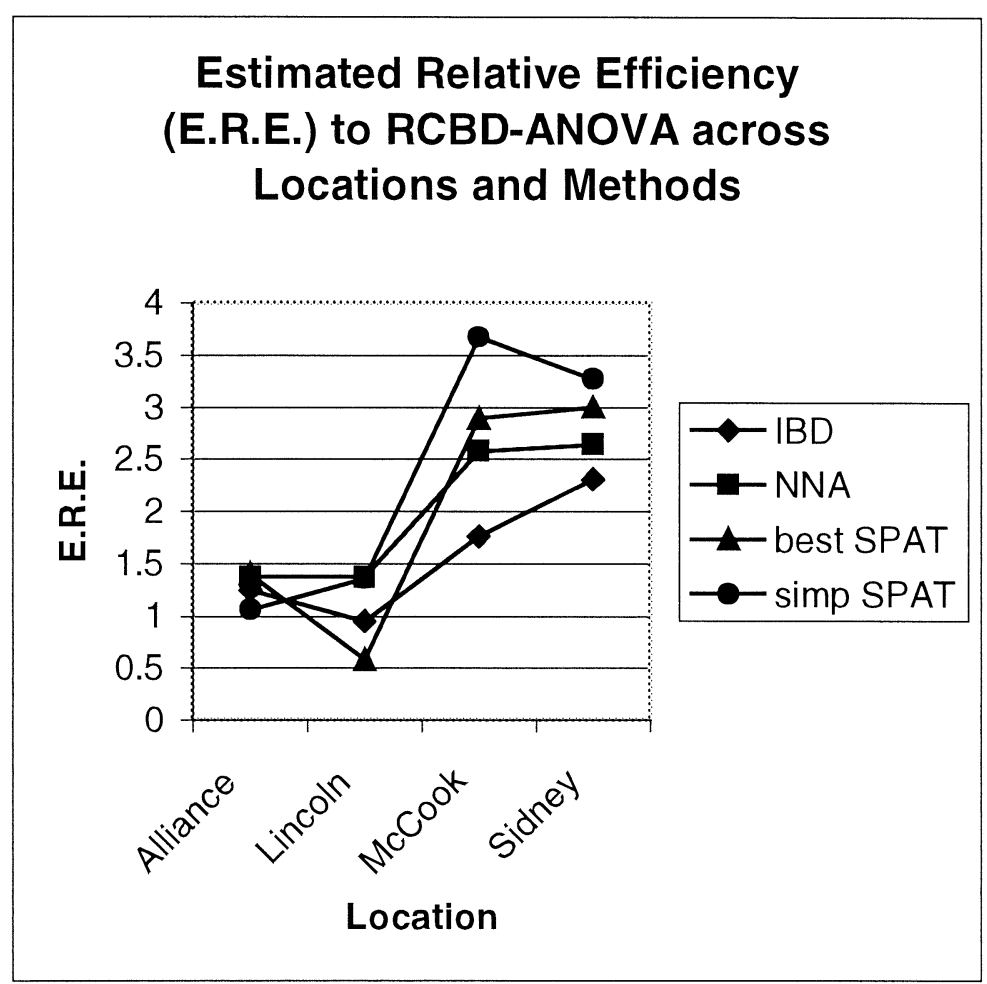

Figure 3

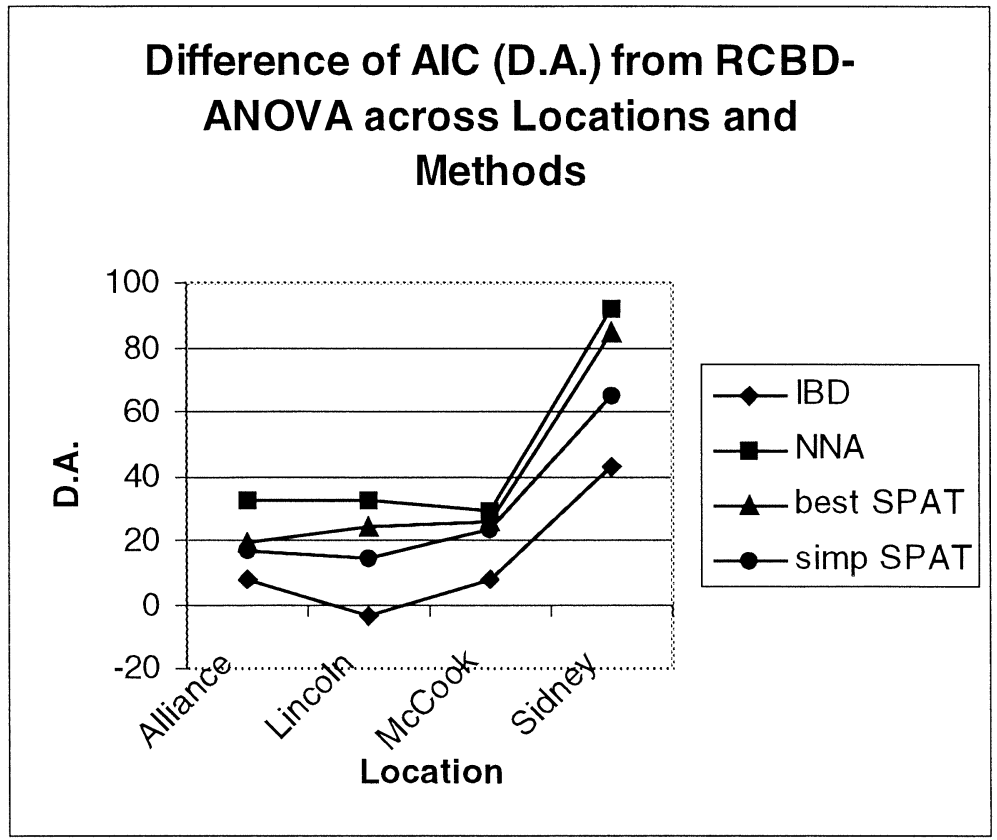


Figure 4

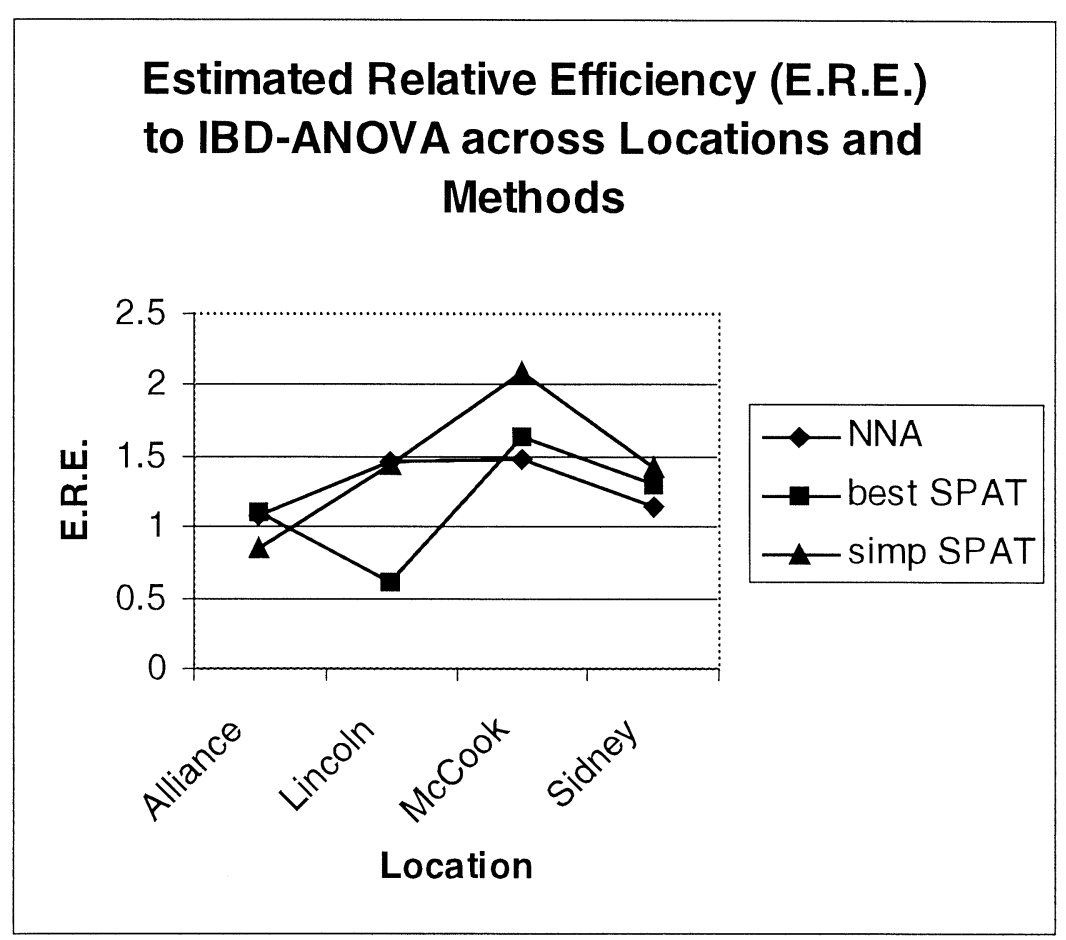

Figure 5

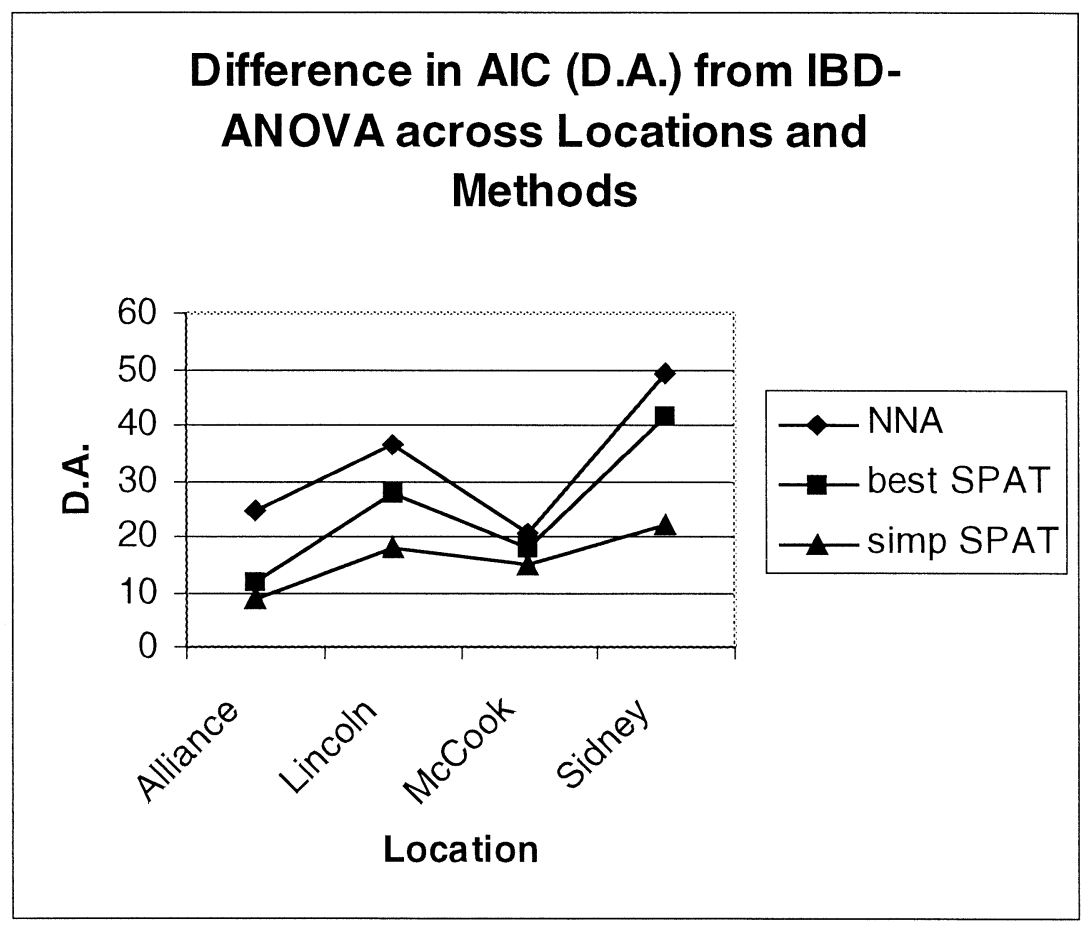

